\title{
Study on the Role of Government in the Alliance of Industry, Education and Research
}

\author{
Liang Jia-qiang \\ School of Management, Shandong University of Technology \\ Zibo City, Shandong Province, China \\ Email: 623537348 [AT] qq.com
}

\begin{abstract}
Economic globalization has greatly promoted the development and integration of global industries and greatly intensified competition and cooperation among enterprises in various countries. On the basis of combing the practical characteristics of the industrial, education and research alliances in various developed countries, this paper makes a comprehensive study on the role that the government should play in the process of the industrial, education and research alliances in China, and puts forward that the government should flexibly use the means of finance, finance and taxation in the industrial, academic and research alliances and play a leading role.
\end{abstract}

Keywords - the Alliance of Industry, Education and Research, the Government, the Role

\section{INTRODUCTION}

The alliance of industry, education and research is the process of complementary advantages and integration of innovative elements resources implemented by enterprises, institutions of higher learning and scientific research units with knowledge production as the link, with the goal of obtaining the overall benefits including economic interests, cultural interests and political interests. Because the cooperation between industry, science and research effectively promotes the joint innovation resources of a country or region and the transformation of scientific and technological achievements, many countries in the world have formulated relevant policies to promote the effective union between industry, science and research. ${ }^{[1]}$

The experience of all countries in the world shows that to vigorously promote cooperation in industry, education and research, it needs the support and joint efforts of all parties. Among them, the role of the government is particularly important to the smooth development of cooperation between industry, education and research. From the international experience, one of the important reasons for the sustained competitive advantage of certain industries in some countries is that the domestic enterprises, universities and scientific research institutions in these countries have established a complex alliance relationship, forming a three-dimensional corps, competing with domestic cooperation, co-operation with the outside world, winning national competitive advantage in some industries, promoting national economic development and moving towards prosperity and strength.

\section{THE PRACTICAL CHARACTERISTICS OF THE ALLIANCE OF INDUSTRY, EDUCATION AND RESEARCH ABROAD}

According to their own purposes, resources and systems, each country has formed a unique joint model and promotion mechanism in the alliance of industry, education and research. From the United States, Britain, Japan, Canada, Germany, the alliance of industry, education and research, with the following more significant characteristics:

2.1 The government is the initiator and main driving force of the alliance of industry, education and research.

(1)The main practical composition of the joint of industry, education and research, in the United States is government, enterprises, scientific research institutions and universities. The position of these four components in the union has a process of transformation: the government is the sponsor of the national industry, education and research joint, can also be said to be one of the earliest joint parties and the first joint funding provider, but after some exploration to form a preliminary reference and imitation mechanism, the government in specific joint projects, especially in the competitive industry joint projects are no longer in a clear dominant position, but by enterprises, scientific research institutions and universities become the main components of joint projects. At the same time, various types of social cooperation intermediary organizations have also participated, which play an important role in venture capital.

There are five models of U.S. industrial, education and research cooperation: science and technology park model, business incubator model, patent licensing and transfer model, high-tech enterprise model, industrial-university cooperative research center and engineering research center model. ${ }^{[2]}$

( 2 ) The British Government not only promotes the joint launch of the Joint Industry, Education and Research, but also promotes and regulates the joint process and provides financial support for the joint process. Government and enterprises have become the main responsibility components of the joint model of British industry, education and research, and universities and research institutions are in a synergistic position. From the beginning, the practice of production, study and research in the United Kingdom embodies the characteristics of careful planning, with a strong joint focus. In the 
1990s, the Department for Industry and Trade published the UK's National Innovation System report, which highlighted policy ideas on the storage, transfer and movement of knowledge in the process of industrial, academic and research cooperation. The United Kingdom mainly promotes investment in technological innovation activities through the formulation of preferential policies covering all aspects of cooperation, strengthens the links between SMEs and universities and research institutions, promotes cooperation between the two sides, and enhances the competitiveness of enterprises, the mode of cooperation is mainly the University of Warwick model and teaching company model in the United Kingdom. ${ }^{[3]}$

( 3 ) It is the characteristic and main form of Japan's industrial revitalization plan to promote the formation of new industries and the adjustment and upgrading of industrial structure, and to promote the international development of domestic industries. The Japanese government has always been in a dominant position in the process of the alliance of industry, education and research, and with its strict industrial planning, it directs the joint practice of industry, education and research in various periods, including joint content, methods, key industries and promotion mechanisms. The Japanese government has not only become the organizer and promoter of the joint practice of industry, education and research, but also the actual conductor and participant. The Japanese government believes that university education and academic research must be closely integrated with the production of industry. In order to promote the cause of cooperative education in industry, education and research, Japan has continuously taken new measures and established a series of systems to promote the development of cooperative education in industry, education and research, and has gained many experiences and practices worthy of study and reference.

( 4 ) For a long time, Canada's higher education research funding is relatively generous, university teachers focus on basic research, contempt for applied research, pay attention to the publication of papers, light scientific research results transfer and development of the phenomenon is more serious. Since the 1990s, with the government tightening the funds for scientific research, the concept of university leaders and scientific research teaching staff has also changed greatly. Professors and scholars have come out of the campus, take the initiative to cooperate with enterprises to establish a longterm development partnership. On the one hand, colleges and universities have realized the transfer of technology and obtained some additional funds, on the other hand, they have accumulated experience in cooperation with enterprises, and have enriched the teaching content, so that teaching and scientific research are more targeted.

( 5 ) Although Germany and the United States and the United Kingdom are very different in economic system, social environment and culture, but belong to the market economy-oriented countries, the practice of cooperation in industry, education and research has much in common, in the formulation of policies are mainly to increase government investment in science and technology, strengthen science and technology legislation, promote the transformation of results, promote and stimulate enterprise development and other means and measures.

In recent years, the focus of German policy has been more on improving technological innovation capabilities, building high-tech enterprises, strengthening the transformation of knowledge, and serving economic construction and social development. Germany's cooperation model of industry, education and research has a school-enterprise cooperative research center model, out-of-school scientific research institutions joint enterprise model. ${ }^{[4]}$

2.2 A variety of mechanisms to promote the healthy development of the alliance of industry, education and research

The Federal Laboratory Technology Transfer Complex, established by the Federal Government of the United States in 1970, is one of the main measures taken by the Federal Government to facilitate the transfer of research results to local governments and businesses. In 1990, the Federal Government began to implement the Advanced Technology Program, which provides start-up funds to enterprises or a coalition of enterprises and scientific research institutions for the development of high-tech applied research and industrialization. After 1994, the National Institute of Standards and Technology established the Joint Special Fund for the Promotion of Manufacturing Technology to support the development of regional manufacturing technology centers with federal funding. In addition, the effective investment mode and the investment organization intervention mode are one of the effective mechanisms of the American industry, education and research union, and the promotion of the secondary diffusion of research results is another effective mechanism of the American industrial, education and research joint.

The British Government has provided a supporting mechanism for research funding and a mechanism for cooperation between government agencies to promote joint industry, education and research. The Connect programed, launched in the mid-to-late 1980s, focuses joint practice on promoting basic science and technology areas of strategic importance to the UK economy, such as information, biology and new materials, requiring projects to be jointly applied for by the business community and universities or research institutions, with 50 per cent funded by government or government-funded research councils and 50 per cent provided by participating enterprises.

The Government of Japan has taken a series of effective measures to promote the joint development of industry, education and research, including: convening scholars and people of insight from all parties to participate in the "joint personnel meeting on research and research" to discuss the relevant strategies of joint research and development; 


\section{THE DEVELOPMENT STATUS OF CHINA'S ALLIANCE OF INDUSTRY, EDUCATION AND RESEARCH}

The early practice of cooperation in industry, education and research can be traced back to the 1950s and 1960s, universities, research institutes and military enterprises joint research and development in nuclear and hydrogen bomb development process. ${ }^{[5]}$ In 1992, " the alliance development project of industry, education and research" launched by the Ministry of Education, the Chinese Academy of Sciences and the State Economic and Trade Commission opened a new chapter of our domestic cooperation in research and development. From this, the movement mechanism of the common development of industry, education and research is gradually formed, and a road of combining science and technology with economy suitable for China's national conditions is explored. After many years of cooperation in industry, education and research, China has created some effective ways of cooperation in the alliance of industry, education and research, such as technology transfer, cooperative development, joint construction of high-tech economic entities, joint construction of engineering and technology research centers, enterprise technology centers, post-doctor workstations and other institutions. ${ }^{[6]}$ Rely on universities and research institutes to train science-technology and management personnel for enterprises, set up a joint promotion association for industry, education and research, strengthen comprehensive cooperative relations between regions and schools, pay attention to international scientific and technological cooperation, organize high-level scientific and technological personnel to carry out diagnostic assessment activities for enterprises.

The emergence and development of these forms of cooperation in industry, education and research provide a new way of thinking for the joint education of colleges and universities, and it is also a fundamental measure to accomplish the task of running a school effectively. This is conducive to improving the quality of teaching, promoting the transformation of scientific and technological achievements into productive forces as soon as possible, facilitating the construction of disciplines and promoting the reform of schools. It is not only in line with the objective law of China's economic development, but also in line with the inevitable trend of the development of higher education in the world, which is conducive to the integration of higher education with international standards. At the same time, it also adapts to the needs of enterprises relying on scientific and technological progress, getting out of difficulties, promoting development and enhancing market competitiveness, so that the relationship between schools and enterprises is closer. In recent years, China's colleges and universities in the alliance of industry, education and research, in educating people continue to make some new attempts, and achieved certain results. According to their own professional characteristics, colleges and universities actively explore the joint education model of industry, education and research. At the same time, training technical personnel for enterprises not only laid a good economic foundation for the development of colleges and universities, but also close the relationship between schools and enterprises. It is beneficial to colleges and universities to serve the economic construction, to deepen teaching reform, to train applied engineering and technical personnel, and to enhance the vitality of colleges and universities in the market competition.

The original intention of China's the alliance of industry, education and research, is to promote the rational flow and allocation of scientific research resources through a close and stable system of exchanges and cooperation between large and medium-sized state-owned enterprises and institutions of higher learning and research institutes. Over the past few decades, the joint development project of industry, education and research has implemented more than 500 state-level key high-tech industrialization projects, achieving new sales revenue of more than 100 billion yuan, profits and taxes of more than 20 billion yuan, foreign exchange, saving nearly 4 billion yuan. Under the guidance of these joint development projects, more than 8,200 joint research and development institutions and economic entities have been jointly built throughout the country. ${ }^{[7]}$

\section{THE ROLE OF THE GOVERNMENT IN THE ALLIANCE OF INDUSTRY, EDUCATION AND RESEARCH}

4.1 The cooperation between industry, education and research is a complex systematic project, which involves all aspects of society, and the nature, tasks, goals and values of different aspects of work are different and even contradictory. How to mobilize all aspects of the force around a common goal, to create the best benefits, is the government should think and do things.

At present, in universities, scientific research institutions and researchers in the one-sided pursuit of academic goals, neglect of the phenomenon of applied research is widespread, the main reason is not only affected by traditional ideas, and China's current relevant policies have a direct relationship. For example, we evaluate the status and level of a university or scientific research institution, mainly depending on the number of papers published in its core journals at home and abroad, the results of completion and appraisal and the number of awards awarded, but there is no evaluation of these units to create economic benefits after the results of scientific research; Similarly, assessing a researcher's achievements or promotions depends mainly on the number of papers he has published and the number of subjects he has undertaken and identified, and it does not matter whether these papers and results produce or can produce real value. Under such policy guidance, it will naturally appear that the unit does not care about the application of research, scientific researchers will be identified after the results of the phenomenon of high court. To overcome such problems and mobilize the enthusiasm of all parties to participate in cooperation in industry, education and research, the Government must take measures in all aspects or formulate corresponding policies and regulations. 
4.2 Taking financial, financial, tax and other means to provide practical conditions for cooperation in industry, education and research.

Science and technology is the main combination point of cooperation between industry, education and research, the transformation of scientific and technological achievements is the key to the success of cooperation between industry, education and research, and the intermediate experimental development stage is an indispensable step for scientific and technological achievements from scientific research to large-scale commercial production. According to statistics, China's annual scientific and technological achievements of about 30,000 items, in the production of stable use and has a certain scale of about $20 \%$, and finally can form an industry of only about $5 \%$, compared with the developed countries more than $50 \%$ of the conversion rate of scientific and technological achievements, our waste of knowledge innovation resources is too big. To solve this problem, only the government from the macro coordination. According to foreign experience, the government can take the following three measures to promote the smooth progress of cooperation between industry, education and research.

(1)Increased funding for scientific research and development, especially in the intermediate and production pilot phases, and the Government provides basic conditions for cooperation in industry, education and research to ensure the rapid transformation of scientific and technological achievements into real productivity.

It should be pointed out that our government's investment in science and technology is only in basic science research, as well as public welfare research and development, excluding intermediate and production experiments. That is to say, in the current structure of science and technology investment in China, there is investment in scientific research in the early stage, technical transformation and production input in the later stage, but there is no investment in intermediate experiments in which scientific and technological achievements are transformed into direct productivity. At present, we emphasize that knowledge innovation is very necessary, but at the same time, we should see that knowledge innovation itself is not equal to economic development, how to quickly translate the results of knowledge innovation into real productivity is the key to the problem. If the transformation can't be realized, innovation can only be empty talk, can only be a semi-finished product with no use value, and the most effective way to transform the real productivity of scientific and technological achievements is to strengthen cooperation in production, learning and research. Therefore, while the government increases the investment in scientific research and development, it should pay more attention to and increase the necessary capital investment for the transformation of scientific and technological achievements, promote the achievement of cooperation in industry, education and research, and promote economic development.

(2) The government formulates policies to encourage enterprises to increase their investment in science and technology, so that enterprises can truly become the main body and beneficiaries of the transformation of scientific and technological achievements, and form an enterprise-centered cooperative operation mechanism for industry, education and research.

It is unrealistic to expect countries to increase investment to address the lack of investment in scientific and technological research and development, and there is no international precedent. According to the experience of some countries, the government's investment in science and technology should be focused on basic scientific research and public welfare research and development, and the investment in applied research and technology development should be mainly enterprise-oriented. The role of the government is to use macro-control means and certain preferential policies to guide all aspects of society to invest in the transformation process of scientific and technological achievements, in order to solve the shortage of capital investment. For various reasons, a considerable number of enterprises in China can't guarantee the withdrawal of $1-2 \%$ of the sales revenue for technology development in accordance with the requirements of the state, and the extracted part is often diverted to other uses. This is another important reason for the lack of capital investment in the process of transforming scientific and technological achievements into productive forces and cooperation in industry, education and research, which directly affects the survival and development of enterprises in the fierce market competition.

It is generally believed that research and development funds accounted for less than $1 \%$ of sales of enterprises difficult to survive in the competitive market economy conditions, to reach $2 \%$ can barely maintain, only to reach more than $5 \%$, enterprises have a strong competitiveness. Therefore, only by formulating corresponding policies and regulations as soon as possible, encouraging enterprises to increase the input of R and D, so that enterprises can truly become the main body to accelerate and improve the conversion rate of scientific and technological achievements, can the government make the cooperation between industry, education and research to establish a virtuous circle of operation mechanism, and promote the healthy development of the economy.

( 3 ) Establish a sound venture capital system, attract capital investment through various channels, and provide adequate financial guarantee for cooperation in industry, education and research to promote the transformation of scientific and technological achievements.

The productivity of the transformation of scientific and technological achievements into reality is generally subject to three stages of scientific research, intermediate experiment and scale production, and the proportion of capital investment is about 1:10:100. For these three stages, although the first stage of investment is small but the risk is very large, because it is basic work, the government as the main body of investment is very necessary. The third stage, although the amount of investment is very large, but because of the interest-driven, diversified investment subjects make the financing is not very difficult. Only the second stage is not only a large amount of investment but also a large risk, so that many investors are 
afraid, the investment subject instability, has become a constraint on scientific and technological achievements into productivity "bottleneck."

( 4 ) The government uses appropriate tax policies to promote the healthy development of cooperation in industry, education and research.

The development and development of new products requires a lot of investment, and before the formation of largescale production, it is difficult to make a profit, and therefore often needs tax relief policy support. At present, China has not for the production and research cooperation to promote the transformation of scientific and technological achievements, encourage enterprises to carry out new product development and development preferential policies, even if the production and research cooperation to set up a pilot base of new technology trial products duty-free period is only three years, and Taiwan Province Hsinchu Science and Industry Park new product duty-free period of 5 years, Malaysia's tax-free period of 10 years, Thailand has 15 years of tax-free period. In contrast, China's tax-free period is short, it is difficult for all parties to obtain the huge benefits brought about by cooperative research and development of new products, affecting the further development of cooperation between industry, education and research.

\section{CONCLUSION}

The development of economic globalization has greatly promoted the integration of enterprises in various countries and brought about unprecedented competition with each other, and the effective development of industry, education and research has provided us with a good way to develop. In the process of making effective use of industry, science and research to enhance national competitiveness and enterprise competitiveness, the government's strong participation in actively promoting the role can't be ignored.

\section{REFERENCES}

【1】 Chen yun. Concept Analysis and Paradigm Construction of Cooperation in Industry, Science and Research, 2012 , 30 (8): 1206-1211.

【2】 Li Pei-nan, Zhao Lan-xiang, Wan Jin-bo. Research on Process Management and Evaluation of Cooperation in Industry, education and Research - Program Management Enlightenment of the Cooperative Research Center of American University of Technology, Science and Technology Management, 2013, 32 (2): 20-27.

【3】 Li Zhi-qiang. Li Ling-yi, New Trends in the Integration of Domestic Production, Research and Development: Education Research at Tsinghua University, 2005.

【4】 Wang Huai, Tang Shuang- fu, etc. Foreign production, research and cooperation model comparison and experience to learn, the agriculture of south,2013.11: 51-53

【5】Zhu Gui-long, Zhang Yi, Chen Kai-hua. The Evolution of International Study in cooperation between industry, education and research, the scientific research,2015.11:1669-1685.

【6】 Ding Ho-de. The alliance of industry, education and research is the foundation of the establishment of a new national system of national policy. Tsinghua University Journal (Philosophy and Society Science Edition),1998,(3):50 - 53.

【7】 Yao Zhen-xiang. The role of British teaching companies in promoting the integration of production and learning. [J].the comparative educational research,1996,(1):33 - 34. 